\title{
Políticas públicas e inclusão social no ensino superior comunitário em Santa Catarina: a Universidade do Extremo Sul Catarinense no período desenvolvimentista (2005-2015)
}

Thaíse Arnold Policarpo*

Alcides Goularti Filho **

\section{Resumo}

A educação superior brasileira, durante muitos anos, foi destinada à alta elite, porém, a partir a dos anos 2000, por meio de políticas públicas, a educação superior passou a ser mais acessível a grupos sociais de baixa renda, a mulheres, a negros e a pessoas com deficiência. Período em que o governo foi mais desenvolvimentista. A presente pesquisa apresenta um estudo sobre o Programa Universidade para Todos (PROUNI), o Fundo de Financiamento Estudantil (FIES), o Artigo 170 do Governo do Estado de Santa Catarina e a Bolsa da Prefeitura Municipal de Criciúma no espaço de uma universidade comunitária, Universidade do Extremo Sul Catarinense (UNESC). O trabalho apresenta análise de dados entre os anos de 2005 a 2015, marcada por uma pesquisa qualitativa, com método dialético. Percebemos, a presença do Estado na instituição por meio das políticas públicas sociais inclusivas, concluímos que as políticas de acesso, identificadas pelos programas estudados, ampliaram as oportunidades de determinados grupos sociais e fomentaram o desenvolvimento da universidade.

Palavras-chave: educação; inclusão social; políticas públicas.

\section{Public policies and social inclusion in community higher education in Santa Catarina: the University of the Far South of Santa Catarina in the developmental period (2005-2015)}

\begin{abstract}
For many years, the Brazilian higher education was designated the high elite, however, since 2000, higher education, through public policies, became more accessible to lowincome social groups, women, black and disabled people period when the government was more developmental. This research presents a study about the PROUNI (University for All Program), the FIES (Student Financing Fund), the Article 170 of the Government of the State of Santa Catarina and the City of Criciúma Scholarship inserted in the space of a Brazilian community college, the UNESC (University of the Extreme South of Santa Catarina). In this work, marked by a qualitative research, with a dialectical method, with data analysis done between 2005-2015. We perceived, the presence of the State in the institution through inclusive social public policies, and we have drawn a conclusion: identified in the studied programs, the access policies, increased the opportunities for certain social groups and promoted the development of the university.
\end{abstract}

Keywords: education; social inclusion; public policies.

JEL: I21; I22; I28.

* Doutoranda do Programa de Pós-Graduação em Desenvolvimento Socioeconômico da Universidade do Extremo Sul Catarinense (UNESC). E-mail: thaisepolicarpo@hotmail.com. Fonte Financiadora: CAPES.

** Doutor em Economia pela Universidade Estadual de Campinas (UNICAMP) e Professor do Programa de Pós-Graduação em Desenvolvimento Socioeconômico da Universidade do Extremo Sul Catarinense. E-mail: agf@unesc.net 


\section{Introdução}

A educação é um direito de todos e deve ser garantida pelo Estado. Ela é consagrada fonte de avanço social e econômico, e de fato é. Porém, não podemos negar que existam outros fatores relevantes para promover o desenvolvimento. A educação, sozinha, não resolverá todas as dificuldades do corpo social. Mas, é importante relatar que o saber é fator primordial para a superação da exclusão social. Conforme escreveu Freire (1987), é inegável a força promovida pela educação e pelo conhecimento, para compreender as contradições do mundo humano, incoerências essas que amarram o desenvolvimento do cidadão.

As políticas públicas PROUNI, FIES, Artigo 170 do Governo do Estado de Santa Catarina e Bolsa Criciúma, nas esferas federal, estadual e municipal, caminharam juntas, promovendo, assim, o desenvolvimento da educação superior no país, no estado e na cidade, além de aumentarem as oportunidades a determinados grupos sociais. A presente pesquisa propõe um estudo sobre essas políticas públicas sociais inclusivas. A relevância deste trabalho encontra-se na essência de avaliar essas políticas públicas como incentivos à educação, consequentemente, e não menos importante, como ferramentas de promoção da emancipação de cidadãos, da inclusão social e da redução das desigualdades; e também, como fontes de desenvolvimento econômico e social.

A Universidade do Extremo Sul Catarinense (UNESC), instituição escolhida para este estudo, é financiada em mais de $30 \%$ pelos fundos públicos, por meio das políticas em estudo. Além disso, mais de 50\% dos universitários da UNESC são beneficiados com um dos quatro programas citados anteriormente. Compreendemos a relevância da Unesc para a sociedade, entendemos a importância do Programa Universidade para Todos (PROUNI), do FIES, do Artigo 170 e da Bolsa Criciúma para os alunos. Portanto, a pesquisa propõe um relato sobre as quatro políticas públicas juntas, em uma universidade comunitária.

É relevante o caráter social dos programas PROUNI, FIES, Artigo 170 e Bolsa Criciúma. A educação foi promovida, além do desenvolvimento intelectual e humano, a inclusão social foi concretizada e o crescimento econômico também. Portanto, são políticas públicas sociais inclusivas importantes. A mudança de governo não pode ser motivo para cessar ou reduzir os investimentos destinados aos programas. Precisamos lutar por e defender a nossa educação, a inclusão de grupos em situação de vulnerabilidade social e a redução das desigualdades entre classes. 
É importante ressaltar que as políticas em estudo estão apresentadas conforme regulamentos do ano de 2015 e que atualmente já houveram modificações nos programas estudados. A seguir o trabalho será conduzido, inicialmente, com uma introdução sobre as políticas públicas educacionais estudadas, posteriormente, seguiremos com uma apresentação dessas políticas, e então traremos as contradições que cercam tais programas. Seguindo com os objetivos do trabalho, vamos expor as representatividades das políticas dentro da Universidade, e por fim as conclusões do artigo.

\section{Políticas Públicas Educacionais}

O ensino superior é o grau de educação que tem apontado crescimento consecutivo nas matrículas desde 1993. Há alguns motivos para este acontecimento. Inicialmente, por conta da globalização do ensino fundamental e do alargamento do ensino médio. Além disso, existiu um retorno de parte da sociedade que já permanecia fora do complexo de ensino e que reingressou para cursar a graduação (IPEA, 2015). Esse crescimento nas matrículas é fruto da interiorização de instituições públicas e dos programas de incentivo ao acesso no ensino superior mantidos pelo Estado.

Considerando que a redução das desigualdades sociais também é elencada como fator primordial para o desenvolvimento de um país, o Estado direciona as políticas educacionais PROUNI, FIES, Artigo 170 e Bolsa Criciúma a determinados grupos sociais. Dessa forma, esses programas propiciam o enfrentamento da exclusão social, com vistas a garantir cidadania a todas as pessoas e a evitar a discriminação contra alguns grupos sociais, como as pessoas com deficiência e cidadãos desprovidos financeiramente.

A fim de exemplificar o que é inclusão social - ou uma maneira de sustentar a batalha contra a exclusão - apresenta-se a seguir uma tabela que mostra a taxa de frequência líquida na educação superior por faixa de renda familiar per capita, de 2000 a 2010.

Tabela 1 - Taxa de frequência líquida na educação superior por faixa de renda familiar per capita (2000-2010) no Brasil (Em \%)

\begin{tabular}{cccc}
\hline Faixas de renda & $\mathbf{2 0 0 0}$ & $\mathbf{2 0 1 0}$ & Variação $(\%)$ \\
\hline Até 1,5 SM & 1,4 & 7,6 & 453,6 \\
$>$ 1,5 SM até 3 SM & 9,0 & 28,3 & 214,1 \\
$>$ 3 SM até 5 SM & 23,5 & 44,9 & 91,4 \\
$>$ 5 SM & 44,6 & 53,0 & 18,7 \\
\hline
\end{tabular}

Fonte: IPEA (2015).

Observação: SM = Salário Mínimo 
Ao se analisar a Tabela 1, percebe-se que a participação de cidadãos com renda familiar de até 1,5 salário mínimo, no ensino superior, aumentou de 11,9\% para 40,8\% do total (IPEA, 2015). Portanto, essas informações não deixam suspeita de que existiu o alargamento de oportunidades e tal acontecimento foi possível graças à implantação das políticas de bolsas. Isso é uma proposta concretizada e bem sucedida de inclusão social.

\subsection{Programa Universidade Para Todos - PROUNI}

O PROUNI, idealizado pelo Governo Federal, foi instituído pela Medida Provisória $\mathrm{n}^{\circ} 213 / 2004$, transformada posteriormente na Lei $\mathrm{n}^{\circ} 11.096 / 2005$, de 13 de janeiro de 2005. Conforme descreve o MEC (2014), a função central da política é a concessão de bolsas de estudos parciais e integrais para graduandos de organizações particulares de ensino superior. As bolsas são destinadas a alunos que não possuam diploma de graduação e tenham renda familiar mensal per capita de até um salário mínimo e meio para bolsas integrais ou de até três salários mínimos para bolsas parciais.

O programa é mantido pelo Governo Federal por meio de isenções fiscais concedidas às universidades. Portanto, o PROUNI não requer investimentos diretos orçamentários. Para integrar o programa, o aluno deve ainda, além de respeitar as exigências de renda, ter realizado a prova do Exame Nacional do Ensino Médio (ENEM). A seleção do aluno e a concessão da bolsa estão diretamente relacionadas com a nota que o estudante atinge no ENEM. Também é necessário ter cursado o ensino médio em escola pública ou ter sido bolsista total em escola particular. As pessoas com deficiência física também participam do processo de seleção e concorrem a bolsas totais. O Ministério da Educação promove novas seleções e concessões a cada semestre.

O PROUNI já distribuiu mais de 1,46 milhão de bolsas, sendo $70 \%$ integrais. Portanto, o programa tem atendido principalmente alunos com renda familiar de até um salário mínimo e meio. Também é relevante ressaltar que a política distribui bolsas especialmente a cursos presenciais e noturnos (MEC, 2014). Pensando nas informações disponibilizadas pelo MEC (2014) de que a política atende principalmente estudantes de baixa renda e de cursos noturnos, concluímos que o PROUNI beneficia principalmente cidadãos com renda familiar baixa e que provavelmente estudam no período noturno porque trabalham durante o dia. 
O PROUNI é também uma política que promove a inclusão social de classes historicamente marginalizadas, atende cidadãos de baixa renda, além de reservar um percentual de bolsas para pessoas com deficiência, negros, indígenas e pardos. É inquestionável que o programa, além de atender seu objetivo central, que é a concessão de bolsas para promoção da educação superior no Brasil, ainda possui um caráter inclusivo. A administração social da política é efetuada pela Comissão Nacional de Acompanhamento e Controle Social do PROUNI (CONAP); e no campo local, pelas Comissões Locais de Acompanhamento e Controle Social do PROUNI (COLAP), instaladas nas universidades integrantes da política.

\subsection{Fundo de Financiamento Estudantil - FIES}

A primeira política de financiamento estudantil foi o Crédito Educativo (CREDUC), constituído em 1975 e propagado no primeiro semestre do ano subsequente. Por motivos distintos, entre os quais a inadimplência, o CREDUC se provou insustentável e foi transformado em FIES (IPEA, 2015). O Fundo de Financiamento Estudantil é regulamentado pela Lei ${ }^{\circ} 10.260$, de 12 de julho de 2001, estabelecido para substituir o Crédito Educativo (BRASIL, 2001).

O Fundo de Financiamento ao estudante do ensino superior compõe um fundo de natureza contábil, direcionado à liberação de financiamento a graduandos de instituições privadas, sendo necessário que a universidade mantenha desempenho satisfatório nas avaliações promovidas pelo Ministério da Educação. O FIES não atende cursos a distância, apenas graduações presenciais de instituições particulares. O estudante interessado em se beneficiar da política deve realizar a prova do Enem.

Os financiamentos outorgados no segundo semestre de 2015 têm taxa de juros de 6,5\% ao ano. Durante o curso, o aluno deve amortizar, a cada três meses, a importância de até $\mathrm{R} \$ 150,00$, atinente à liquidação de juros sobre o financiamento. Após o fim do curso, o universitário terá 18 meses de carência para iniciar o pagamento. Nesse período, continua pagando a taxa de juros nas mesmas regras. Encerrado o período de carência, a dívida pode ser liquidada pelo aluno em até três vezes o tempo financiado do curso mais doze meses.

O Fundo de Financiamento Estudantil (FIES), desde o início de suas atividades até o ano de 2009, foi responsável por 600 mil novos contratos. A partir do ano de 2010, quando iniciaram algumas mudanças nas normas do FIES, até o ano de 2013, o programa 
liberou mais de um milhão de novos financiamentos. Tal informação comprova o quanto a política tem contribuído para o desenvolvimento da educação superior brasileira e também para a prosperidade social, permitindo que estudantes antes isolados desse nível de ensino tenham a oportunidade de nele ingressar.

A sustentação de que o FIES se mantém como um programa de auxílio ao avanço social é comprovada também após uma análise do perfil dos alunos por ele contemplados. Cerca de $60 \%$ dos estudantes beneficiados com a política são mulheres, aproximadamente $75 \%$ são egressos de escolas públicas e em torno de $50 \%$ são cidadãos que possuem renda de até um salário mínimo per capita. Portanto, entre outros, um grupo significativo dos contratos firmados pelo programa, é marcado por mulheres, pobres e alunos de escola púbica.

\subsection{Artigo 170 do Governo do Estado de Santa Catarina}

A Constituição do Estado de Santa Catarina em vigência foi consolidada em 1989. Após a consagração do atual texto constitucional catarinense, é comum que sejam acrescentadas emendas sugeridas pela Câmara Legislativa do Estado. O Artigo 170, inscrito em nossa Constituição, é uma política pública que concede bolsas de estudos e bolsas de pesquisa. O programa mantém suas atividades assegurado nos comandos constitucionais e em algumas Leis Complementares.

As bolsas de estudos oriundas do Artigo 170 são concedidas a alunos de cursos de graduação presenciais de instituições privadas. São direcionadas a estudantes de baixa renda e a pessoas com deficiência. Para ser beneficiado, o estudante, deve ser egresso de escola pública ou ter sido bolsista total em escola particular. Também deve ser brasileiro e não possuir diploma de curso superior (GOVERNO DE SANTA CATARINA, 2017).

O ano de 2004 foi marcado por passeatas e pela presença dos alunos na Assembleia Legislativa. As reivindicações eram de ampliação do Artigo 170.Após diversas discussões entre o governo estadual e as representações populares, associações e movimento estudantil, finalmente foi aprovado por unanimidade pela Assembleia Legislativa o projeto de ampliação do Artigo 170. Em solenidade no Palácio do Estado, foi sancionada a Lei Complementar $n^{\circ} 281$, de 20 de janeiro de 2005 - que já sofreu algumas alterações, mas continua sendo uma das principais guias do Artigo 170 até os dias atuais. 
A Lei Complementar descreveu em seu texto, de maneira mais ampla, as funções do programa; regulamentou e definiu como deveria funcionar o Artigo 170. Além disso, apresentou os deveres dos alunos contemplados: bom desempenho nas notas, participação em programas e projetos sociais com visão educativa e a entrega de documentos exigidos para a concessão do benefício. Também, deixou claro quais seriam os compromissos das instituições de ensino: montar a comissão para a liberação das bolsas, disporem de projetos de extensão para a interação dos alunos, e descrever em seus balanços os recursos públicos recebidos por meio do programa.

Também aparece no texto da referida Lei o compromisso do Estado: concessão de bolsas de estudo e bolsas de pesquisa para a liquidação total ou parcial das mensalidades dos estudantes regularmente matriculados em cursos de graduações. O repasse do recurso é realizado diretamente para a universidade e o benefício é disponibilizado para o aluno a cada semestre. O estudante desprovido economicamente e a pessoa com deficiência ganhará bolsa de estudo ou de pesquisa integral.

De acordo com a Constituição Estadual e as Leis Complementares que regulamentam o programa, o Artigo 170 é uma política pública criada pelo Governo do Estado de Santa Catarina que contempla alunos com descontos em suas mensalidades. A seleção é realizada pelas universidades e a porcentagem do desconto determinado pela instituição de ensino, não podendo ser inferior a $25 \%$. Também são concedidas bolsas de pesquisa. Os recursos são designados, proporcionalmente, de acordo com a quantidade de estudantes matriculados nos cursos de graduação de cada universidade. Entre os anos de 2009 e 2015 o governo catarinense já investiu R\$105.258.129,14 no programa.

\subsection{Bolsa Prefeitura Municipal de Criciúma}

A Fundação Educacional de Criciúma (FUCRI) foi instituída pela Lei no 697 de 22 de julho de 1968, que foi revogada e consolidada pela Lei Ordinária no 2.272, de 21 de dezembro de 1987. A instituição - com personalidade jurídica, de direito privado, instituída pelo poder público municipal - teve seus estatutos aprovados na Lei Ordinária $\mathrm{n}^{\mathrm{o}} 2.272$, de 21 de dezembro de 1987. Este documento já previa em seu texto a distribuição de bolsas de estudos destinadas a alunos de baixa renda e residentes em Criciúma, sendo estes auxílios custeados pela Prefeitura Municipal, que tinha como prefeito José Augusto Hülse. Em 15 de outubro de 1993, A Lei Ordinária no 2.879, 
revogou a Lei anterior. A revogação se fez necessária para atender às novas exigências da Lei Orgânica Municipal.

Segundo a Lei Complementar $n^{\circ}$ 96, de 14 de fevereiro de 2013, no que se refere à distribuição das bolsas na educação superior (CRICIÚMA, 2013, p. 01):

Art. $2^{\circ}$ As bolsas, estágios e auxílios financeiros previstos no artigo anterior serão concedidos conforme seguintes critérios:

a) Bolsa Trabalho: por intermédio de processo seletivo, com normas fixadas em edital;

b) Auxílio financeiro, compreendendo a bolsa carente e deficiente: critérios estabelecidos pela comissão criada pela Lei Complementar $n^{\circ} 33 / 04$;

c) Bolsa de Estudo ou Ajuda de Custo a Atletas do Município: por critérios estabelecidos pela Fundação Municipal de Esportes.

Portanto, de maneira semelhante aos programas PROUNI, FIES e Artigo 170 do Governo do Estado de Santa Catarina, as bolsas distribuídas pelo Município de Criciúma também atende classes sociais desfavorecidas historicamente. O repasse é realizado direto para a universidade e a distribuição dos auxílios financeiros é realizado por meio de processo seletivo e análise da comissão responsável por tais atividades. No contexto histórico das bolsas distribuídas pela Prefeitura de Criciúma para os alunos do ensino superior, houve mais de dez Leis estabelecidas para ajustar a organização das distribuições dos benefícios. Ou seja, o longo dos anos, ela foi sendo ajustada conforme as necessidades dos alunos, da universidade e da administração municipal.

A Prefeitura Municipal de Criciúma atende, além dos alunos da Unesc, estudantes de outras instituições estabelecidas na cidade, por exemplo a Associação Beneficente da Indústria Carbonífera de Santa Catarina (SATC) e a Escola Superior de Criciúma (ESUCRI). Em 14 de dezembro de 2015, por meio da Lei Ordinária nº 6.682, a Administração Municipal estabeleceu a possibilidade de convênio com as escolas particulares de nível superior de Criciúma mediante compensação tributária. Importante relatar que essa compensação não se estende à UNESC, uma vez que a instituição tem garantido, na Lei Orgânica Municipal, outras maneiras de subsídios.

\section{Contradições dos Programas PROUNI, FIES, Artigo 170 e Bolsa Criciúma}

As políticas de incentivo ao acesso à educação superior, disponibilizadas pelo Estado, não são as únicas maneiras de enfrentar as dificuldades educacionais que os brasileiros sofrem, é preciso melhorar a base educacional pública. Porém, tendo em vista 
a falta de oferta do sistema público de ensino superior, o Estado desenvolve tais políticas conectadas com o setor particular de ensino.

Com isso, uma das críticas direcionadas aos programas é o incentivo à privatização da educação. Após uma análise histórica da educação superior brasileira, foi possível perceber que o domínio das organizações particulares não é oriundo, apenas, dos programas citados anteriormente. Mas é anterior até mesmo à criação da primeira universidade no Brasil. A diversificação do sistema educacional foi defendida por muitos como sendo a liberdade educacional e, no decorrer dos tempos, a educação superior foi sendo conduzida para o setor privado. Portanto, no momento de implantação das políticas públicas em estudo, o sistema público de ensino superior já se apresentava insuficiente para atender a demanda.

Outra dificuldade apontada pelos estudiosos é a evasão dos alunos bolsistas. Segundo eles, apenas o desconto ou a isenção nas mensalidades não são suficientes para garantir a permanência dos estudantes nas universidades particulares. Sobre a estabilidade do aluno, devem ser levados em consideração vários fatores; a permanência se torna mais complexa quando se tratam de classes excluídas. A realidade brasileira é que há uma diferença grande entre o número de matrículas e o número de concluintes de cursos de graduações. Essa disparidade encontra-se em todo o sistema, tanto público quanto privado.

Portanto, não podemos avaliar os programas como os causadores dessa disparidade. O PROUNI, o FIES, o Artigo 170 do Governo de Santa Catarina e a Bolsa da Prefeitura Municipal de Criciúma não podem ser percebidos apenas com uma submissão aos princípios do capitalismo (FONTELE, 2013). Conforme Poulantzas (1985), o Estado mantém certa distância das forças produtivas, ou seja, da política econômica. E, esse Estado não pode ser compreendido como um instrumento à disposição do sistema capitalista, consequentemente as políticas implantadas pelos governos não devem ser analisadas apenas por esse viés. O Estado é também, segundo o autor, um espaço de enfrentamentos; e, na sociedade civil isso não é diferente.

Outra situação exposta em relação aos programas é a suspeita qualidade do ensino proposto pelas instituições privadas. As legislações que estabelecem as políticas de bolsas ressalvam a necessidade de avaliação positiva das instituições de ensino, junto ao Ministério da Educação, para participarem dos processos de liberação dos incentivos. Portanto, é princípio das políticas públicas que as universidades mantenham boa qualidade no ensino. 
O autor Portelli (1990) já havia relatado que os direitos sociais devem ser garantidos pelo Estado e, mesmo com a estatização, essa garantia não mudará. Tais situações, os vínculos entre governantes e governados, devem ser estudadas como fator de hegemonia. Podemos compreender assistência como sendo o controle da pobreza, a influência do antagonismo social. A assistência reduz os efeitos do capitalismo e os programas em estudo podem ser classificados como políticas de assistência, pois amparam classes sociais desfavorecidas, promovendo, dessa forma, a diminuição das consequências do sistema capitalista.

\section{As Políticas de Inclusão Social na Universidade do Extremo Sul Catarinense}

A UNESC iniciou suas funções no ano de 1968 e foi transformada em universidade em 1997. Algumas mudanças aconteceram em função da luta da comunidade, das manifestações populares para que o sul-catarinense fosse contemplado com uma universidade. A sociedade se uniu e conquistou a universidade comunitária, oriunda de uma Fundação Educacional. Pode-se dizer, portanto, que a UNESC nasceu pela luta da comunidade regional.

A Universidade do Extremo Sul Catarinense, atualmente, é mantida também por subsídios dos Governos, ou seja, as políticas públicas de educação superior são importantes para manter a instituição. Existem diversas políticas de apoio, porém destacam-se na UNESC as escolhidas para serem analisadas para esta pesquisa: o PROUNI, FIES - ambos do Governo Federal -, o Artigo 170 do Governo do Estado de Santa Catarina e a Bolsa distribuída pela Prefeitura Municipal de Criciúma.

A UNESC apresentou um crescimento em sua receita após a implantação dos programas em estudo, citados no parágrafo anterior, durante o período em análise (de 2005 a 2015), conforme a Tabela 2.

Percebemos que houve um crescimento da instituição. Esse desenvolvimento é comprovado pelo aumento de sua receita, considerando que existe inflação. A ampliação foi possível, principalmente, pelos investimentos estatais, oriundos dos Governos Federal, Estadual (de Santa Catarina) e Municipal (de Criciúma). Dito de outra forma, os fundos públicos possibilitaram o crescimento da universidade e ampararam cidadãos por meio de políticas públicas sociais inclusivas. Quanto ao número de alunos em nível de graduação, percebemos que entre os anos de 2010 - 2014 a quantidade de estudantes 
aumenta: a instituição ganhou mais de 1.200 alunos nesse período em que o país apresentou uma administração mais desenvolvimentista.

Tabela 2 - Receita total e número de alunos em nível de graduação da UNESC, Criciúma (SC) (2005-2015)

\begin{tabular}{ccc}
\hline Ano & Receita $($ em R\$) & Número de Alunos \\
\hline 2005 & $59.642 .766,81$ & 9.209 \\
2006 & $66.063 .992,76$ & 9.626 \\
2007 & $71.426 .465,56$ & 9.675 \\
2008 & $74.213 .547,29$ & 9.315 \\
2009 & $79.175 .331,81$ & 9.461 \\
2010 & $85.467 .253,41$ & 9.012 \\
2011 & $97.648 .121,00$ & 9.061 \\
2012 & $105.721 .623,00$ & 9.342 \\
2013 & $118.690 .741,00$ & 9.844 \\
2014 & $147.060 .168,00$ & 10.797 \\
2015 & $165.905 .589,75$ & 10.469 \\
\hline
\end{tabular}

Fonte: UNESC (2017).

Observação: Para o número de alunos foi considerado o segundo semestre de cada ano.

\subsection{Programa Universidade para Todos na Universidade do Extremo Sul Catarinense}

O PROUNI passou a atender os alunos da UNESC no ano de 2006, um ano após sua criação. Desde sua implantação, houve um constante crescimento no número de bolsas distribuídas. Confirmamos, com isso, que a presença do Estado foi se alargando na instituição por meio das políticas públicas, conforme a Tabela 3.

Tabela 3 - Bolsas Distribuídas pelo PROUNI e participação total sobre o número de alunos de graduação na UNESC, Criciúma (SC) (2005-2015)

\begin{tabular}{cccc}
\hline Ano & Alunos de Graduação & $\begin{array}{c}\text { Bolsas } \\
\text { Distribuídas }\end{array}$ & Participação (em \%) \\
\hline 2006 & 9.626 & 76 & 0,79 \\
2007 & 9.675 & 232 & 2,40 \\
2008 & 9.315 & 405 & 4,35 \\
2009 & 9.461 & 547 & 5,78 \\
2010 & 9.012 & 720 & 7,99 \\
2011 & 9.061 & 863 & 9,52 \\
2012 & 9.342 & 958 & 10,25 \\
2013 & 9.844 & 1.256 & 12,76 \\
2014 & 10.797 & 1.569 & 14,53 \\
2015 & 10.469 & 1.679 & 16,04 \\
\hline
\end{tabular}

Fonte: UNESC (2017).

Observação: Para o número de alunos foi considerado o segundo semestre de cada ano. 
É relevante o crescimento que teve o PROUNI nos últimos anos, tanto em nível nacional, como na esfera mais local da UNESC. Essa expansão foi importante para a instituição; o programa foi uma ferramenta de fortalecimento, mas também uma política de inclusão social. Podemos relatar que foram mais de 1.600 oportunidades para negros, indígenas, pessoas com deficiência física, pardos e pobres. O programa atende também um número significativo de mulheres, portanto outra maneira de maneira de inclusão.

Tabela 4 - Bolsas distribuídas por sexo (em \%) pelo PROUNI na UNESC, Criciúma (SC) (2006-2015)

\begin{tabular}{ccc}
\hline Ano & Homens Bolsistas & Mulheres Bolsistas \\
\hline 2006 & 40,79 & 59,21 \\
2007 & 37,07 & 62,93 \\
2008 & 36,79 & 63,21 \\
2009 & 37,66 & 62,34 \\
2010 & 37,92 & 62,08 \\
2011 & 38,93 & 61,07 \\
2012 & 41,44 & 58,56 \\
2013 & 39,97 & 60,03 \\
2014 & 40,54 & 59,46 \\
2015 & 39,25 & 60,75 \\
\hline
\end{tabular}

Fonte: UNESC (2017).

Como é possível ver na Tabela 4, o número de mulheres atendidas pelo PROUNI na instituição é superior à quantidade de homens beneficiados pelo programa. A política pública demarcada pelo PROUNI não estabelece o sexo do aluno como critério de seleção, porém é relevante que na instituição em estudo sobressaia o número de mulheres atendidas - um grupo que historicamente foi marginalizado em um país de pensamentos machistas como o Brasil. Durante muitos anos, as mulheres foram afastadas da educação superior e quando se permitiu a elas o ingresso nesse nível de ensino o curso era prédeterminado pela própria sociedade.

Ou seja, as mulheres representam um grupo em situação de desvantagem devido ao histórico de dominação que vivenciou. Enxergar o PROUNI como garantidor de oportunidades a essa parte da sociedade - que continua na luta por seus direitos, que ainda sofre preconceito e violência de todas as maneiras em um índice bastante alto - é ter a certeza que o programa não pode acabar.

A UNESC também apresentou crescimento, contribuiu para esse crescimento as políticas públicas educacionais garantidas pelo Estado. O PROUNI foi um programa importante para o crescimento da UNESC. A Tabela 5 mostra, em reais, o quanto foi possível investir na própria instituição graças à isenção de imposto garantido pela política. 
Tabela 5 - Valores de participação do PROUNI (em R\$) sobre a receita total na UNESC, Criciúma (SC) (2006-2015)

\begin{tabular}{cccc}
\hline Ano & Receita Total & Isenções Fiscais & Participação (em \%) \\
\hline 2006 & $66.063 .992,76$ & $217.314,00$ & 0,33 \\
2007 & $71.426 .465,56$ & $1.183 .079,00$ & 1,66 \\
2008 & $74.213 .547,29$ & $2.223 .497,00$ & 3,00 \\
2009 & $79.175 .331,81$ & $3.365 .038,00$ & 4,25 \\
2010 & $85.467 .253,41$ & $4.631 .255,00$ & 5,42 \\
2011 & $97.648 .121,00$ & $5.991 .732,00$ & 6,14 \\
2012 & $105.721 .623,00$ & $7.702 .387,00$ & 7,29 \\
2013 & $118.690 .741,00$ & $9.910 .808,00$ & 8,35 \\
2014 & $147.060 .168,00$ & $13.731 .993,00$ & 9,34 \\
2015 & $165.905 .589,75$ & $16.471 .307,00$ & 9,93 \\
\hline
\end{tabular}

Fonte: UNESC (2017).

Conforme descrito anteriormente o programa PROUNI não proporciona investimento direto às instituições. $\mathrm{O}$ governo federal concede isenções fiscais às universidades como contrapartida. As isenções concedidas à UNESC revelam um crescimento constante, atualmente, representam quase $10 \%$ da receita da universidade. Em 2015 a instituição foi dispensada pelo governo, do pagamento de imposto superior a 16 milhões, um valor expressivo e que se permitiu investir na instituição. Devemos considerar, também, que a UNESC tem um custo para manter os bolsistas do PROUNI.

Diante de todas as informações apresentadas, concluímos o quanto o PROUNI foi importante para a UNESC, para a comunidade e, principalmente, para os estudantes. Entendemos que valores oriundos do programa não foram efetivamente pagos à instituição, mas é uma parte da receita que deixou de ser gasta com impostos e passou a ser investida na própria instituição. Por meio do PPROUNI, houve inclusões concretizadas. Com isso, percebemos a relevância da política, entendemos o caráter social do programa e, sobretudo, compreendemos que esse programa não pode cessar suas atividades.

\subsection{Fundo de Financiamento Estudantil na Universidade do Extremo Sul Catarinense}

A política institucionalizada por meio do FIES, diferente do programa PROUNI, não distribui bolsas de estudo, porém o FIES é uma política relevante de fomento ao ingresso na educação superior, pois proporciona ao aluno a oportunidade de um financiamento. O FIES atende também uma parcela de estudantes bolsistas parciais do PROUNI. A política apresenta participação significativamente os alunos da instituição. 
Tabela 6 - Financiamentos concedidos pelo FIES e participação total sobre o número de alunos de graduação na UNESC, Criciúma (SC) (2005-2015)

\begin{tabular}{lccc}
\hline Ano & $\begin{array}{c}\text { Alunos de } \\
\text { Graduação }\end{array}$ & Financiamentos Concedidos & Participação (em \%) \\
\hline 2005 & 9.209 & 146 & 1,59 \\
2006 & 9.626 & 125 & 1,30 \\
2007 & 9.675 & 118 & 1,22 \\
2008 & 9.315 & 89 & 0,96 \\
2009 & 9.461 & 100 & 1,06 \\
2010 & 9.012 & 152 & 1,69 \\
2011 & 9.061 & 371 & 4,09 \\
2012 & 9.342 & 923 & 9,88 \\
2013 & 9.844 & 1.458 & 14,81 \\
2014 & 10.797 & 2.181 & 20,20 \\
2015 & 10.469 & 2.190 & 20,92 \\
\hline
\end{tabular}

Fonte: UNESC (2017).

A Tabela 6 mostra o crescimento que teve o FIES. Esse aumento se concentra, principalmente, entre os anos de 2011 e 2014, período em que a UNESC apresentou crescimento no número de estudantes de graduação. Em dez anos, foram mais de dois mil financiamentos concedidos aos alunos da UNESC. Percebemos também que entre 2005 e 2008 houve uma redução no número de financiamentos concedidos. Essa realidade foi revertida por meio da intervenção estatal e, posteriormente, a quantidade de benefícios cresceu.

Tabela 7 - Financiamentos Concedidos por sexo (em \%) pelo FIES na UNESC, Criciúma (SC), (2005-2015)

\begin{tabular}{ccc}
\hline Ano & Homens Beneficiados & Mulheres Beneficiadas \\
\hline 2005 & 32,88 & 67,12 \\
2006 & 29,60 & 70,40 \\
2007 & 31,36 & 68,64 \\
2008 & 31,46 & 68,54 \\
2009 & 27,00 & 73,00 \\
2010 & 31,58 & 68,42 \\
2011 & 34,23 & 65,77 \\
2012 & 34,24 & 65,76 \\
2013 & 36,28 & 63,72 \\
2014 & 35,44 & 64,56 \\
2015 & 34,79 & 65,21 \\
\hline
\end{tabular}

Fonte: UNESC (2017).

Com a interferência do Governo, foi possível manter o programa e percebemos o crescimento do FIES na universidade em estudo. A política foi fortalecida por meio da intervenção dos governos, ou seja, a administração intercedeu para garantir a política 
pública a determinados grupos sociais. A Tabela 7 apresenta o financiamento por sexo e em destaque a maior representatividade dos recursos para o sexo feminino. Isso é a presença do Estado dentro de uma universidade comunitária. O crescimento dos programas PROUNI e FIES, na UNESC, está associado ao modelo de governo mais desenvolvimentista, no período de 2003 - 2015.

Existe uma disparidade entre homens e mulheres contemplados, tanto pelo programa PROUNI quanto pela política FIES. O senso disponibilizado pelo Inep em 2015 apresentou que o número de mulheres que ingressam na educação superior, em todo o país, é de 53\% e homens, 46\%;55\% das matrículas são efetuadas por mulheres e 44\%, por homens; já as concluintes da graduação representam 59\% do total e os concluintes, $40 \%$. Portanto, em todo o país já existe uma diferença entre homens e mulheres que ingressam, efetuam matrículas e concluem o curso.

Assim como o programa PROUNI, o FIES apresentou crescimento em todo o Brasil. E na universidade em estudo ocorreu o mesmo. A evolução dos programas foi relevante para o cumprimento das metas de Governo em promover a inclusão social e priorizar a educação, neste caso a educação superior. O FIES e seu crescimento na UNESC representam o Governo Federal na instituição. O Governo foi alargando seu espaço na universidade por meio das políticas públicas, apoderando-se de uma universidade comunitária para promover a inclusão social de grupos antes excluídos da educação superior. Amparou os alunos e também a instituição.

Tabela 8 - Valores de participação do FIES (em R\$) sobre a receita bruta total na UNESC, Criciúma (SC) (2005-2015)

\begin{tabular}{cccc}
\hline Ano & Receita Total & Valor Recebido & $\begin{array}{c}\text { Participação }(\mathbf{e m} \\
\text { \%) }\end{array}$ \\
\hline 2005 & $59.642 .766,81$ & $640.821,00$ & 1,07 \\
2006 & $66.063 .992,76$ & $647.212,00$ & 0,98 \\
2007 & $71.426 .465,56$ & $558.134,00$ & 0,78 \\
2008 & $74.213 .547,29$ & $538.310,00$ & 0,73 \\
2009 & $79.175 .331,81$ & $1.016 .112,00$ & 1,28 \\
2010 & $85.467 .253,41$ & $1.803 .709,00$ & 2,11 \\
2011 & $97.648 .121,00$ & $4.546 .256,00$ & 4,66 \\
2012 & $105.721 .623,00$ & $9.733 .124,00$ & 9,21 \\
2013 & $118.690 .741,00$ & $21.486 .892,00$ & 18,10 \\
2014 & $147.060 .168,00$ & $27.097 .600,00$ & 18,43 \\
2015 & $165.905 .589,75$ & $31.651 .430,00$ & 19,08 \\
\hline
\end{tabular}

Fonte: UNESC (2017). 
O número de financiamentos concedidos pelo FIES para os alunos da UNESC apresentou expansão crescente, ou seja, os valores repassados à instituição por meio da política aumentaram, conforme a Tabela 8. Isso promoveu o fortalecimento do programa na instituição e permitiu que pobres e pessoas com deficiência física tivessem as oportunidades de ingresso alargadas na educação superior. Com esse aumento, tivemos mais pessoas em situação vulnerável frequentando a universidade. Porém, o FIES assim como o PROUNI são políticas de Governo e não políticas de Estado. As pessoas tornaram-se dependentes desses programas, as mudanças de Governo podem gerar modificações e até mesmo encerrar as atividades promovidas por tais políticas.

\subsection{Artigo 170 do Governo do Estado de Santa Catarina na Universidade do Extremo Sul Catarinense}

O Artigo 170 é uma política institucionalizada por Santa Catarina e um programa relevante para os estudantes e universidades do Estado. O Estado de Santa Catarina incentiva a educação superior por meio da política Artigo 170, programa que é fruto de muitas lutas sociais. Atualmente, a política é relevante para Universidade do Extremo Sul Catarinense, e também para os seus alunos. Compreendemos isso com a apresentação da Tabela 9.

Tabela 9 - Bolsas Distribuídas pelo Artigo 170 e participação total sobre o número de alunos de graduação na UNESC, Criciúma (SC) (2005 - 2015)

\begin{tabular}{cccc}
\hline Ano & Alunos de Graduação & Bolsas Distribuídas & Participação (em \%) \\
\hline 2005 & 9.209 & 2.222 & 24,13 \\
2006 & 9.626 & 2.203 & 22,89 \\
2007 & 9.675 & 1.989 & 20,56 \\
2008 & 9.315 & 1.800 & 19,32 \\
2009 & 9.461 & 1.922 & 20,31 \\
2010 & 9.012 & 1.668 & 18,51 \\
2011 & 9.061 & 2.076 & 22,91 \\
2012 & 9.342 & 1.974 & 21,13 \\
2013 & 9.844 & 1.688 & 17,15 \\
2014 & 10.797 & 1.403 & 12,99 \\
2015 & 10.469 & 1.218 & 11,63 \\
\hline
\end{tabular}

Fonte: UNESC (2017).

É possível perceber que houve uma queda no número de bolsas distribuídas. Essa redução concentra-se, principalmente, entre os anos de 2011 e 2015, quando houve uma diminuição de 858 bolsas disponibilizadas pelo Artigo 170. A redução no número de 
beneficiados é decorrente da alteração na porcentagem dos descontos disponibilizados pelas bolsas parciais. O regulamento do Artigo 170 determina que 25\% é o valor mínimo de redução na mensalidade, mas as porcentagens podem variar de acordo com cada instituição. Na Universidade do Extremo Sul Catarinense, ocorreram momentos em que a porcentagem do desconto era menor, por isso, tivemos um número maior de alunos atendidos. Porém, esse desconto já chegou a 40\%, ou seja, o valor do auxílio aumentou, com isso a quantidade de estudantes atendidos teve de ser reduzida.

Tabela 10 - Bolsas Distribuídas por sexo (em \%) pelo Artigo 170 na UNESC, Criciúma (SC) (2005-2015)

\begin{tabular}{ccc}
\hline Ano & Homens Bolsistas & Mulheres Bolsistas \\
\hline 2005 & 27,23 & 72,77 \\
2006 & 28,37 & 71,63 \\
2007 & 30,72 & 69,28 \\
2008 & 30,72 & 69,28 \\
2009 & 30,96 & 69,04 \\
2010 & 30,46 & 69,54 \\
2011 & 31,02 & 68,98 \\
2012 & 30,50 & 69,50 \\
2013 & 32,11 & 67,89 \\
2014 & 31,00 & 69,00 \\
2015 & 30,62 & 69,38 \\
\hline
\end{tabular}

Fonte: UNESC (2017).

O Artigo 170, assim como o PROUNI e o FIES, concede um número maior de bolsas para as mulheres, conforme a Tabela 10. Sabemos que o grupo feminino está mais presente nas universidades, porém existe uma diferença grande entre a quantidade de benefícios distribuídos para as mulheres e para os homens. Além da inclusão dos grupos sociais determinados pela política, é evidente a inclusão também de mulheres na UNESC. Enquanto tivemos, em média, 30\% das bolsas disponibilizadas para os homens, $70 \%$ foram destinadas as mulheres. O curso mais contemplado pelo programa, no período de 2005 a 2015, foi o de Ciências Contábeis, com 1.989 bolsas distribuídas. Os cursos que menos recebem auxílio do Artigo 170 são os cursos tecnólogos.

Os valores repassados à UNESC para o custeio do programa Artigo 170 evoluíram, conforme a Tabela 11. Os recursos destinados à instituição, de acordo com o regulamento do Artigo 170, está associado ao número de estudantes da universidade. A Universidade do Extremo Sul Catarinense apresentou um aumento na quantidade de estudantes na graduação, por isso existiu um crescimento nos repasses do Estado para a instituição. 
Tabela 11 - Valores de participação do Artigo 170 (em R\$) sobre a receita bruta total na UNESC, Criciúma (SC) (2005-2015)

\begin{tabular}{cccc}
\hline Ano & Receita Total & Valores Recebidos & $\begin{array}{c}\text { Participação (em } \\
\text { \%) }\end{array}$ \\
\hline 2005 & $59.642 .766,81$ & $2.001 .189,00$ & 3,36 \\
2006 & $66.063 .992,76$ & $2.238 .869,00$ & 3,39 \\
2007 & $71.426 .465,56$ & $1.755 .879,00$ & 2,46 \\
2008 & $74.213 .547,29$ & $2.315 .284,00$ & 3,12 \\
2009 & $79.175 .331,81$ & $2.967 .776,00$ & 3,75 \\
2010 & $85.467 .253,41$ & $2.342 .717,00$ & 2,74 \\
2011 & $97.648 .121,00$ & $3.644 .769,00$ & 3,73 \\
2012 & $105.721 .623,00$ & $3.187 .061,00$ & 3,01 \\
2013 & $118.690 .741,00$ & $3.196 .790,00$ & 2,69 \\
2014 & $147.060 .168,00$ & $3.039 .671,00$ & 2,07 \\
2015 & $165.905 .589,75$ & $3.353 .677,00$ & 2,02 \\
\hline
\end{tabular}

Fonte: UNESC (2017).

\subsection{Bolsas Prefeitura Municipal de Criciúma na Universidade do Extremo Sul Catarinense}

Os auxílios financeiros disponibilizados pela Prefeitura Municipal de Criciúma para a UNESC, no decorrer da história, aconteceram de diversas maneiras. Aos alunos do município de Criciúma, o governo municipal distribui bolsas de estudos. O município garante diferentes modalidades de bolsas: bolsa trabalho/estagiário, bolsa atleta e auxílio financeiro para pobres e pessoas com deficiência. As informações apresentadas na Tabela 12 se referem ao auxílio financeiro disponibilizado a cidadãos de baixa renda e a pessoas com deficiência física.

Tabela 12 - Bolsas Distribuídas pelo Município de Criciúma e participação total sobre o número de alunos de graduação na UNESC, Criciúma (SC) (2005-2015)

\begin{tabular}{cccc}
\hline Ano & Alunos de Graduação & $\begin{array}{c}\text { Bolsas } \\
\text { Distribuídas }\end{array}$ & Participação em \% \\
\hline 2005 & 9.209 & 145 & 1,57 \\
2006 & 9.626 & 149 & 1,55 \\
2007 & 9.675 & 184 & 1,90 \\
2008 & 9.315 & 233 & 2,50 \\
2009 & 9.461 & 302 & 3,19 \\
2010 & 9.012 & 528 & 5,86 \\
2011 & 9.061 & 679 & 7,49 \\
2012 & 9.342 & 918 & 9,83 \\
2013 & 9.844 & 910 & 9,24 \\
2014 & 10.797 & 619 & 5,73 \\
2015 & 10.469 & 592 & 5,65 \\
\hline
\end{tabular}

Fonte: UNESC (2017). 
A administração municipal de Criciúma tem amparado seus alunos de graduação e promovido o acesso de indivíduos de baixa renda e de pessoas com deficiência física ao ensino superior, por meio da distribuição de bolsas de estudos parciais e integrais. Assim como aconteceu com o FIES, no mesmo período em que a universidade apresentou aumento no número de alunos em nível de graduação, as bolsas disponibilizadas pela Prefeitura também cresceram de maneira mais significativa, entre os anos de 2011 e 2013, como expressa a Tabela 13. Podemos destacar que as políticas públicas, portanto, tiveram participação no aumento de estudantes da UNESC nesse período.

É importante relatar também que durante alguns anos o município promoveu a distribuição de bolsas conhecida como "Minha Chance", foi uma maneira da instituição quitar uma dívida que tinha com a cidade. Os dados apresentados a seguir se referem apenas aos auxílios financeiros instituídos pela Lei Orgânica do município, pois o programa "Minha Chance" foi uma política temporária. Os valores para o custeio das bolsas distribuídas são repassados diretamente à universidade.

Tabela 13 - Valores de participação da Bolsa Criciúma (em R \$) sobre a receita bruta total na UNESC, Criciúma (SC) (2005-2015)

\begin{tabular}{cccc}
\hline Ano & Receita Total & Valores Recebidos & Participação (em \%) \\
\hline 2005 & $59.642 .766,81$ & $299.912,00$ & 0,50 \\
2006 & $66.063 .992,76$ & $335.701,00$ & 0,51 \\
2007 & $71.426 .465,56$ & $352.635,00$ & 0,49 \\
2008 & $74.213 .547,29$ & $360.400,00$ & 0,49 \\
2009 & $79.175 .331,81$ & $571.329,00$ & 0,72 \\
2010 & $85.467 .253,41$ & $1.225 .232,00$ & 1,43 \\
2011 & $97.648 .121,00$ & $1.897 .588,00$ & 1,94 \\
2012 & $105.721 .623,00$ & $3.322 .563,00$ & 3,14 \\
2013 & $118.690 .741,00$ & $3.303 .696,00$ & 2,78 \\
2014 & $147.060 .168,00$ & $1.933 .965,00$ & 1,32 \\
2015 & $165.905 .589,75$ & $2.126 .757,00$ & 1,28 \\
\hline
\end{tabular}

Fonte: UNESC (2017).

A Universidade do Extremo Sul Catarinense foi estabelecida por Lei Municipal. Dessa forma, a legislação municipal destina investimento a essa instituição. Os valores repassados à UNESC promovem o crescimento da instituição e, consequentemente, o desenvolvimento regional. Porém, além de garantir o fomento à economia, os benefícios distribuídos pela Prefeitura Municipal de Criciúma amparam as pessoas da cidade, pois garantem o alargamento de oportunidades aos criciumenses para ingressar na educação superior. Portanto, reduzir investimento na universidade é também reduzir investimento no desenvolvimento e, ainda mais grave do que isso, é diminuir o investimento nas 
pessoas. As bolsas distribuídas pelo município à UNESC já apresentaram redução, desamparando, dessa forma, os alunos que dependem do auxílio do programa. Novamente, estamos vivenciando a exclusão de determinados grupos da educação superior.

\section{A presença do Estado na Universidade do Extremo Sul Catarinense}

Percebemos o Estado na universidade comunitária em estudo, por meio das políticas públicas PROUNI, FIES, Artigo 170 do Governo do Estado de Santa Catarina e Bolsa Criciúma. Os programas possibilitam às classes sociais antes excluídas da educação superior uma oportunidade de nela ingressar. Propiciou a grupos marginalizados pelo contexto histórico de nosso país a chance de emancipação por meio da educação, portanto podemos classificar as políticas públicas sociais inclusivas como a representação da presença do Estado, conduzindo a sociedade a realizar os enfrentamentos necessários.

Entre 2005 e 2015, os grupos sociais determinados pelos programas e as mulheres tiveram alargadas as oportunidades de ingressar na educação superior graças às políticas públicas sociais inclusivas em estudo. Compreendemos que nem todos os beneficiados chegam a concluir a graduação, mas, ainda assim, entendemos que foram oportunidades oferecidas a classes sociais desfavorecidas pelo contexto histórico brasileiro. A Tabela 14 apresenta os benefícios distribuídos pelos programas em análise.

Tabela 14 - Benefícios distribuídos pelos programas e participação total sobre o número de alunos na UNESC, Criciúma (SC) (2005-2015)

\begin{tabular}{cccc}
\hline Ano & Alunos de Graduação & Alunos Beneficiados & Participação (em \%) \\
\hline 2005 & 9.209 & 2.513 & 27,29 \\
2006 & 9.626 & 2.553 & 26,52 \\
2007 & 9.675 & 2.523 & 26,08 \\
2008 & 9.315 & 2.527 & 27,13 \\
2009 & 9.461 & 2.871 & 30,35 \\
2010 & 9.012 & 3.068 & 34,04 \\
2011 & 9.061 & 3.989 & 44,02 \\
2012 & 9.342 & 4.773 & 51,09 \\
2013 & 9.844 & 5.312 & 53,96 \\
2014 & 10.797 & 5.772 & 53,46 \\
2015 & 10.469 & 5.679 & 54,25 \\
\hline
\end{tabular}

Fonte: UNESC (2017).

Houve comprometimento com os grupos sociais em situação de vulnerabilidade.

Percebemos esse comprometimento do Governo Federal quando as políticas públicas PROUNI e FIES aumentaram o número de alunos beneficiados. E, também do Governo 
do Estado de Santa Catarina por meio do Artigo 170; além das administrações do Município de Criciúma, com os repasses financeiros para distribuição de bolsas de estudos.

É inquestionável o número crescente de bolsas distribuídas pelos programas na Universidade do Extremo Sul Catarinense, principalmente entre os anos de 2011 e 2014. Nesse momento, o Brasil manteve uma administração mais desenvolvimentista, os governos apresentaram preocupações com as questões sociais; e, o aumento de benefícios distribuídos entre os alunos da educação superior foi consequência desse modo de gestão.

As políticas sociais inclusivas em estudo foram e são relevantes para a Unesc e principalmente para a sociedade. Os anos analisados para esta pesquisa marcam o momento em que o Estado assume sua verdadeira função. Porém, não podemos nos esquecer dos dizeres de Marx (2003), quando relatou que é o homem o responsável pela libertação de uma classe social; e é também o responsável pelo fim do sofrimento da humanidade. Segundo Freire (1987), a libertação de um grupo social apenas acontecerá por meio da emancipação dos indivíduos e, para que essa emancipação seja concretizada, é necessário haver políticas sociais inclusivas.

Podemos afirmar, portanto, que as políticas públicas em estudo são mecanismos usados pelos Governos para amparar a sociedade e proporcionar oportunidade de libertação de determinadas classes sociais, estas identificadas pelos próprios programas. Além de propiciar a esses grupos, a possibilidade de emancipação individual. Por meio da educação superior, amparada pelas políticas públicas sociais inclusivas. Isso sustenta quando relatamos que são políticas públicas que não podem cessar.

É relevante a participação do Estado na receita bruta total da universidade, como demonstra-se na Tabela 15. Entendemos que os valores oriundos do PROUNI não são investimentos que entram nas contas da universidade, porém são quantias que não saem da instituição. Durante o período em estudo, a UNESC foi aumentando sua dependência em relação aos fundos públicos.

Assistimos nos últimos anos a parcial estatização das finanças da UNESC promovida pelos Governos federal, estadual e municipal. O presente estudo apresentou informações apenas sobre os cursos de graduação, mas é relevante lembrar que a instituição é amparada também por bolsas para os cursos de pós-graduação. Na esfera municipal, é importante que se saiba que os alunos são também amparados por outras formas de auxílios e por outros municípios. Exemplos disso são as diversas cidades da 
região que garantem o transporte aos alunos da instituição. Com a estatização parcial financeira de 2005 a 2015, a instituição teve folga orçamentária.

Tabela 15 - Representatividade dos programas na UNESC, Criciúma (SC) (2005-2015)

\begin{tabular}{cccc}
\hline Ano & $\begin{array}{c}\text { Receita Bruta } \\
\text { Total }\end{array}$ & Receita dos Programas & $\begin{array}{c}\text { Participação em } \\
\text { \% }\end{array}$ \\
\hline 2005 & $59.642 .766,81$ & $2.941 .922,66$ & 4,93 \\
2006 & $66.063 .992,76$ & $3.439 .095,96$ & 5,21 \\
2007 & $71.426 .465,56$ & $3.849 .727,12$ & 5,39 \\
2008 & $74.213 .547,29$ & $5.437 .491,22$ & 7,33 \\
2009 & $79.175 .331,81$ & $7.920 .254,97$ & 10,00 \\
2010 & $85.467 .253,41$ & $10.002 .913,51$ & 11,70 \\
2011 & $97.648 .121,00$ & $16.080 .344,89$ & 16,47 \\
2012 & $105.721 .623,00$ & $23.945 .135,39$ & 22,65 \\
2013 & $118.690 .741,00$ & $37.898 .185,30$ & 31,93 \\
2014 & $147.060 .168,00$ & $45.803 .229,44$ & 31,15 \\
2015 & $165.905 .589,75$ & $53.603 .171,41$ & 32,31 \\
\hline
\end{tabular}

Fonte: UNESC (2017).

A estatização financeira parcial da UNESC garantiu inclusão social e folga orçamentária, porém gerou também uma dependência dos fundos públicos. Na época de bonança, alargam-se as atividades acadêmicas; nos momentos de crise e ajuste fiscal, a instituição tem dificuldades financeiras. São as consequências da volta de um governo conservador na Universidade do Extremo Sul Catarinense. Portanto, a dependência financeira em relação ao Estado é contraditória para uma universidade comunitária: em tempos de estatização, gerou folga orçamentária e promoveu a inclusão social; em tempos de crise ameaça as finanças da instituição.

\section{Conclusão}

Podemos afirmar que a educação é fonte de desenvolvimento social e econômico. A educação superior brasileira, durante anos, foi destinada à alta elite. Com o passar dos anos, houve uma modificação quanto a isso. A partir dos anos 2000, por meio de políticas públicas, a educação superior passou a ser mais acessível a grupos sociais de baixa renda, a mulheres, a negros e a pessoas com deficiência física. As instituições estatais desempenham suas funções, mas é inegável que são insuficientes para atender toda a demanda existente. Com isso, para garantir o desenvolvimento da educação superior, o Estado utilizou a estrutura de instituições não estatais.

No decorrer da pesquisa percebemos que a presença do Estado na Universidade do Extremo Sul Catarinense foi se expandindo. Em 2015, a instituição teve mais de 30\% 
de suas receitas oriundas das políticas públicas e mais de 50\% de seus alunos em nível de graduação eram beneficiados com um dos quatro programas analisados. A estatização parcial é sustentada pelas políticas públicas; os alunos da universidade são amparados pelos Governos nos seus diferentes níveis.

As modificações nas regras do Exame Nacional do Ensino Médio (ENEM), como o aumento da taxa de inscrição, refletiram em uma redução no número de inscritos para o exame. Enquanto no ano de 2016 foram 9,6 milhões de inscritos, em 2017 esse número caiu para 7,6 milhões. Tendo em vista que a participação no Enem é indispensável para se ter acesso a um dos dois programas federais (PROUNI e FIES), é possível verificar que teremos uma redução no número de alunos beneficiados por essas políticas.

O Estado de Santa Catarina passa por dificuldades, conforme matéria do Jornal Diário Catarinense, de 23 de agosto de 2017, o cenário é dramático e as contas não fecham. Com isso, nasce também uma preocupação com relação ao Artigo 170. Quanto ao município de Criciúma, a universidade já vem sofrendo com a falta de recursos. No ano de 2016, a prefeitura, por meio de Lei, reconheceu uma dívida de quase cinco milhões com a UNESC. Os alunos já estão enfrentando dificuldades: no primeiro semestre de 2017, houve uma redução de cerca de 200 bolsas.

Encerramos esta pesquisa concordando com Celso Furtado de que o desenvolvimento irá acontecer quando existir um equilíbrio entre o campo econômico e o social. Portanto, a educação não será a única responsável pelo desenvolvimento econômico, tampouco pela redução das desigualdades sociais. Precisamos de um Estado comprometido com outras questões, como a melhor distribuição da renda. Dessa forma, se almejamos um Brasil mais desenvolvido, teremos de lutar por maior equiparação social e econômica.

\section{Referências}

BRASIL. Lei ${ }^{\circ}$ 10.260, de 12 de julho de 2001. Dispõe sobre o Fundo de Financiamento ao estudante do Ensino Superior e dá outras providências. Disponível em: <http://www.planalto.gov.br/ccivil_03/leis/LEIS_2001/L10260.htm>. Acesso em: 20 fev. 2017.

Lei $n^{\circ}$ 11.096, de 13 de janeiro de 2005. Institui o Programa Universidade para Todos - PROUNI, regula a atuação de entidades beneficentes de assistência social no ensino superior; altera a Lei no 10.891, de 9 de julho de 2004, e dá outras providências. Disponível em: <http://www.planalto.gov.br/ccivil_03/_ato20042006/2005/lei/L11096.htm>. Acesso em: 20 fev. 2017. 
CRICIÚMA. Lei Complementar $\mathbf{n}^{\circ}$ 96, de 14 de fevereiro de 2013. Dispõe sobre os recursos previstos no art. 129 da Lei Orgânica Municipal destinados à Fundação Educacional de Criciúma - FUCRI e dá outras providências. Disponível em: $<$ https://leismunicipais.com.br/a1/sc/c/criciuma/lei-complementar/2013/10/96/leicomplementar-n-96-2013-dispoe-sobre-os-recursos-previstos-no-artigo-129-da-leiorganica-municipal-destinados-a-fundacao-educacional-de-criciuma-fucri-e-da-outrasprovidencias?q=96>. Acesso em: 23 ago. 2017.

Lei Ordinária $\mathbf{n}^{\circ} \mathbf{2 2 7 2}$, de 21 de setembro de 1987. Consolida a legislação referente à Fundação Educacional de Criciúma e dá outras providências.

Lei Ordinária $\mathbf{n}^{\circ}$ 2879, de 15 de outubro de 1993. Consolida a legislação referente à Fundação Educacional de Ciciúma, revoga a lei nº 2272/87, e dá outras providências.

Lei Ordinária $\mathbf{n}^{\circ}$ 6682, de 14 de dezembro de 2015. Autoriza o Poder Executivo Municipal a celebrar convênio com escolas particulares de nível superior no Município mediante compensação tributária, para fins que específica, e dá outras providencias.

DIÁRIO CATARINENSE. Florianópolis, 23 ago. 2017. Disponível em: <http://dc.clicrbs.com.br/sc/colunistas/moacir-pereira/noticia/2017/08/crise-financeiraatinge-governo-de-santa-catarina-9876922.html>. Acesso em: 24 ago. 2017.

FONTELE, T. L. L. PROUNI: uma reflexão sobre o, a voz de beneficiários do programa. 2013. 103 f. Dissertação (Mestrado em Políticas Públicas e Gestão da Educação Superior) - Universidade Federal do Ceará, Fortaleza. Disponível em: <http://www.repositorio.ufc.br/bitstream/riufc/8038/1/2013_dis_tllfontele.pdf >. Acesso em: 6 mar. 2017.

FREIRE, P. Pedagogia do oprimido. 17. ed. Rio de Janeiro: Paz e Terra S/A, 1987. 184 p.

GOVERNO DE SANTA CATARINA. 2017. Disponível em: <http://www.sc.gov.br/>. Acesso em: 1 mar. 2017.

IPEA. Políticas sociais: acompanhamento e análise. Brasília: Governo Federal, 2015. Disponível

<http://www.ipea.gov.br/portal/index.php?option=com_content\&view=article\&id=2581 2\&Itemid=9>. Acesso em: 20 jun. 2016.

MARX, K.; ENGELS, F. Sagrada família. São Paulo: Boitempo, 2003. 286 p. Tradução de: Marcelo Backes.

MEC. A democratização e expansão da educação superior no país 2003 - 2014. Brasília: Mec, 2014. 106 p. Disponível em: $<$ http://portal.mec.gov.br/index.php?option=com_docman\&view=download\&alias $=167$ 62-balanco-social-sesu-2003-2014\&Itemid=30192 > . Acesso em: 21 fev. 2017.

PORTELLI, Hugues. Gramsci e o bloco histórico. São Paulo: Paz e Terra, 1990. 
POULANTZAS, Nicos. O estado, o poder e o socialismo. Edições Graal: Rio de Janeiro, 1985.

UNESC. Universidade do Extremo Sul Catarinense. Disponível em: <http://www.unesc.net/portal/>. Acesso em: 06 set. 2017.

UNIEDU. Programa de Bolsas Universitárias de Santa Catarina. Disponível em: <http://www.uniedu.sed.sc.gov.br/>. Acesso em: 25 jul. 2017. 